Page 1 of 15

\title{
Emergency Presentations of Acute Biliary Pain: Changing Patterns of Management in a Tertiary Institute.
}

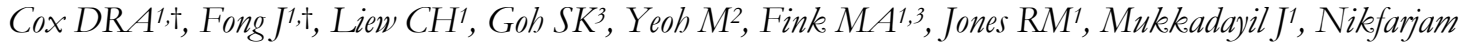
$M^{1,3}$, Perini $M V^{1,3}$, Rumler $G^{1}$, Starkey $G^{1}$, Christophi $C^{1,3}$, Muralidharan $V^{1,3}$

1. HPB \& Transplant Unit, Austin Hospital, Melbourne, Australia.

2. Emergency Department, Austin Hospital, Melbourne, Australia.

3. The University of Melbourne Department of Surgery, Austin Hospital, Melbourne, Australia. † Co-first authors.

\section{Corresponding author:}

A/Prof Vijayaragavan Muralidharan E v.muralidharan@unimelb.edu T +61 (03) 94965000

Department of Surgery, University of Melbourne, Austin Health, Level 8 Lance Townsend Building, Studley Rd, Heidelberg, Melbourne, Victoria 3084, Australia.

W www.austinsurgery.unimelb.edu.au

The corresponding author has no grants relating to this article to disclose.

Keywords: biliary pain - biliary colic - cholecystitis - laparoscopic cholecystectomy - emergency general surgery - cholecystectomy - representations - ASU

\section{Word Count:}

Abstract: 246, Main Text: 2695, 2 tables, 1 supporting information document.

Abbreviations: ED - Emergency Department, HPB - Hepatopancreatobiliary, UGI - Upper Gastrointestinal, SD - Standard deviation, RUQ - Right Upper Quadrant [abdomen], RR - Relative Risk, 95\% CI - 95\% Confidence Interval, ERCP - Endoscopic retrograde cholangiopancreatogram.

This is the author manuscript accepted for publication and has undergone full peer review but has not been through the copyediting, typesetting, pagination and proofreading process, which may lead to differences between this version and the Version of Record. Please cite this article as doi: $10.1111 /$ ans.14898 


\begin{abstract}
Introduction: Acute biliary pain is the most common presentation of gallstone disease. Untreated patients risk recurrent pain, cholecystitis, obstructive jaundice, pancreatitis and multiple hospital presentations. We examine the outcome of implementing a policy to offer laparoscopic cholecystectomy on index presentation to patients with biliary colic in a tertiary hospital in Australia.
\end{abstract}

Methods: This is a retrospective cohort study of adult patients presenting to the emergency department (ED) with biliary pain during three twelve-month periods. Outcomes in Group A, three years prior to policy implementation, were compared with groups two and seven years post (Groups $B$ and C). Primary outcomes were representations to ED, admission rate and time to cholecystectomy.

Results: A total of 584 patients presented with biliary colic during the three study periods. Of these 391 underwent cholecystectomy with three Strasberg Type A bile leaks and no bile duct injuries. The policy increased admission rates $(\mathrm{A}=15.8 \%, \mathrm{~B}=62.9 \%, \mathrm{C}=29.5 \%, \mathrm{p}<0.001)$ and surgery on index presentation $(\mathrm{A}=12.0 \%, \mathrm{~B}=60.7 \%, \mathrm{C}=27.4 \%, \mathrm{p}<0.001)$. There was a decline in time to cholecystectomy (days) $(A=143, B=15, C=31, p<0.001)$, postoperative length of stay (days) $(A=3.6$, $\mathrm{B}=3.2, \mathrm{C}=2.0, \mathrm{p}<0.05)$ and representation rates to $\mathrm{ED}(\mathrm{A}=42.1 \%, \mathrm{~B}=7.1 \%, \mathrm{C}=19.9 \%, \mathrm{p}<0.001)$. There was a decline in policy adherence in the later cohort.

Discussion: Index hospital admission and cholecystectomy for biliary colic decreases patient representations, time to surgery, postoperative stay and complications of gallstone disease. This study demonstrates the impact of the policy with initial improvement, the danger of policy attrition and the need for continued reinforcement. 
Page 3 of 16

This article is protected by copyright. All rights reserved. 


\section{MAIN TEXT}

\section{Introduction}

Epidemiological studies have demonstrated that approximately $10-25 \%$ of the Western adult population have gallstones, the prevalence of which increases with age and amongst women within reproductive years. (1-3) Acute biliary pain is one of the commonest symptoms of gallstone disease (4), presenting typically as abdominal pain in the epigastrium and right upper quadrant within 30 to 60 minutes after meals and usually lasting for one to five hours. A recent Scandinavian study, with a large observational cohort, found that approximately $20 \%$ of patients with incidental cholelithiasis went on to develop symptoms or complications of gallstone disease over a 17 year period. (5) Complications of symptomatic gallstones include recurrent pain, cholecystitis, choledocolithiasis, cholangitis and pancreatitis which may require admission to hospital with or without definitive treatment. $(6-10)$

Early cholecystectomy is widely accepted as the preferred treatment for acute presentations of biliary colic. (11) Demands on acute surgical beds, access to operating theatres and the availability of on-call surgeons, especially in the public hospital domain, have led to patients with uncomplicated biliary colic often being treated as outpatients on an elective basis. A prolonged time from presentation to eventual cholecystectomy is, however, associated with increased risk of complicated gallstone disease. (12) The delay often results in greater morbidity for patients, with longer operative times, longer length of stay and increased healthcare costs. (13) 
At the Austin Hospital, a tertiary referral centre in Melbourne, Victoria, a policy to treat patients presenting with biliary colic with definitive surgery on the same admission was instituted in 2007. The aim of this study was to examine the impact of this policy on patient outcomes, with respect to the time from presentation to definitive surgery, and the overall effect on patient representations to the emergency department (ED). 


\section{Patients and Methods}

A retrospective review of all patients presenting with acute biliary pain, as documented in an ED database, in three twelve-month periods were chosen for comparison. The data from ED records was correlated against information from our prospective clinical database maintained by the Department of Surgery for the two surgical units (HPB/Transplant Unit, UGI/Endocrine Unit) primarily involved in the emergency management of patients with biliary pathology. Electronic hospital records were interrogated for supplementary information. The first study period was from $1^{\text {st }}$ October 2004 to $30^{\text {th }}$ September 2005 (Group A) three years prior to implementation of the policy. The second period from 1st October 2009 to 30th September 2010 (Group B) reviewed outcomes two years after the institution of the policy. The second period was chosen five years after the first and two years after the implementation of the policy to allow routine practice to be established. The third study period, from 1 ${ }^{\text {st }}$ October 2014 to 30 $0^{\text {th }}$ September 2015 (Group C), was chosen to further assess the long-term impact and adherence to the policy seven years after implementation.

Acute biliary pain was defined as right upper quadrant/epigastric abdominal pain with sonographic evidence of cholelithiasis, in the absence of a leucocytosis, cholestatic liver function tests, sonographic evidence of cholecystitis or a documented temperature $>37.5^{\circ} \mathrm{C}$, as diagnosed by an Emergency Department Physician or Surgical Registrar. Patients were excluded if they had previously undergone cholecystectomy, other surgical intervention for gallstone disease or if an alternative diagnosis had been made during admission. 
Primary outcomes were representations to the ED, admission rate and time to laparoscopic cholecystectomy. All data was entered into SPSS 15.0 (Chicago, USA). The Chi-squared and MannWhitney tests were used for continuous and categorical variables respectively. Values were considered significant if they had a $\mathrm{p}$ value $<0.05$. A comparative analysis was conducted for outcomes between Groups A, B and C. The relative risk/probability (RR) of outcomes between groups was calculated, in addition to the $95 \%$ confidence interval of the RR.

\section{Results}

Tables I and II summarise the data and indicate statistical significance. Tables S1 and S2 in the supporting document illustrate the causes for patient representation in this cohort and representation rates previously reported in the literature.

During the first study period (Group A, 2004-2005) 158 patients presented to the ED with a diagnosis of biliary colic. The mean age of the patients was $54(\mathrm{SD} \pm 17)$ years. Of these only 60 $(38.0 \%)$ had an ultrasound performed during their initial assessment in the ED.

In this group, $25(15.8 \%)$ patients were admitted of whom $19(12.0 \%)$ had an operation performed during the index admission. Of the remainder, 87 (55.1\%) were discharged with advice to be followed up by their family practitioner or by a surgeon in their private rooms while $46(29.1 \%)$ were discharged with a hospital outpatient appointment. Of the 133 patients discharged, 56 (42.1\%) represented to the hospital at least once. A second representation was recorded in 15 patients $(11.2 \%)$ and five patients $(3.8 \%)$ had a third representation. The majority of the 56 patients returned 
with recurrent biliary colic $(\mathrm{n}=39)$ while others had acute cholecystitis $(\mathrm{n}=11)$, obstructive jaundice $(\mathrm{n}=5)$ and gallstone pancreatitis $(\mathrm{n}=1)$.

A definitive operation was performed in 102 patients (64.6\%) for their pathology. Of those discharged home with plans for an elective operation, $83(62.4 \%)$ had an eventual laparoscopic cholecystectomy, at an average time of 144 days $(S D \pm 255)$ with mean length of stay of 3.6 days $(S D$ $\pm 5.3)$.

During the second study period (Group B, 2009-2010), two years after implementation of the policy, 280 patients presented with biliary colic, with a lower average age of $47(\mathrm{SD} \pm 19)$. A significantly greater number of patients $(\mathrm{n}=219,78.2 \%)$ had a diagnostic ultrasound performed during their stay in the ED and two thirds were admitted ( $\mathrm{n}=176,62.9 \%$ ). Of those, 170 had an inpatient laparoscopic cholecystectomy and six were admitted for non-operative management.

Of the remaining 104 patients discharged home from the ED, 20 represented (19.2\%) of whom 19 had biliary colic and one developed obstructive jaundice. In this patient cohort of representations seven $(35 \%)$ were admitted and underwent inpatient laparoscopic cholecystectomy, four (20\%) had non-operative admissions, nine patients were once again discharged. Of those nine, seven $(35 \%)$ were booked for elective cholecystectomy, one $(5 \%)$ had public clinic follow up and one $(5 \%)$ to private surgeon follow up. A further three patients represented a second time of whom one was admitted for inpatient laparoscopic cholecystectomy, one booked for elective cholecystectomy four days later and the last opted for private surgeon follow up and was discharged. The average time to 
operation was much shorter at 16 days $(\mathrm{SD} \pm 47)$ with an average length of stay of 3.2 days $(\mathrm{SD} \pm$ 2.8).

During the third study period (2014-2015), 146 patients presented with biliary colic, with a similar age demographic to the second cohort (mean $44 \pm 17$ years). Eighty-four patients $(60 \%)$ underwent initial diagnostic ultrasound during their presentation in the ED. There was a significant reduction in index admissions compared to the second cohort with only 43 (29.5\%) patients being admitted. Of those admitted, 40 patients (93.0\%) underwent cholecystectomy during the same admission. Of the three patients who did not receive inpatient cholecystectomy at the Austin Hospital, two were transferred to a private hospital, while the remaining patient was deemed medically unfit for surgery.

The remaining 103 patients were discharged home from the ED. The majority ( $\mathrm{n}=59)$ were followed up in the outpatient clinic while 44 were discharged with advice to follow up with their GP or private surgeon. Representations involved 29 patients (28.2\%), 21 with biliary colic, six with cholecystitis and two with pancreatitis. In the cohort of the 29 patients who represented, 18 were subsequently admitted for inpatient laparoscopic cholecystectomy, one patient refused surgery and 11 of the patients were again discharged. Of the latter 11, six were booked for elective laparoscopic cholecystectomy, three elected for private follow up and one referred to the hospital outpatient department. Four patients had further representations to the ED. Of the 103 patients who were discharged a total of 44 went on to have laparoscopic cholecystectomy at our institution.

A total of 84 cholecystectomies were performed within the third cohort of patients. The average time to operation was 31 days ( $\mathrm{SD} \pm 55)$, with average length of stay of 2 days $(\mathrm{SD} \pm 2)$. 


\section{Discussion}

Our results demonstrate that the policy of admitting patients with biliary colic on their index presentation to the ED results in fewer representations to hospital. This is consistent with results from a systematic review of early vs. late laparoscopic cholecystectomy for biliary colic by Gurusamy et al. (11), which reported on a single randomized trial of 75 participants that found a $35 \%$ readmission rate in the 'delayed' surgery group. (14) In Western Australia, a review of patients on the elective cholecystectomy waiting-list previously demonstrated a readmission rate of $5 \%$ (15). Rutledge et al. reviewed 251 patients with delayed surgery for biliary colic and showed a representation rate of $22 \%$ for biliary colic and $20 \%$ for complicated biliary disease (16). Similarly Guirguis and Taylor observed that $22 \%$ of elective laparoscopic cholecystectomy patients experienced complications prior to their procedure. (17) A US study examining the follow-up after discharge from the ED with biliary colic identified only $12.6 \%$ of patients as having had an elective cholecystectomy within two years of that presentation. (18)

It should be noted that a number of additional barriers exist that may add to the lengthy delay in surgical follow up and subsequent elective cholecystectomy. These include difficulties at the patientlevel such as inability to schedule and keep appointments and at a systems-level where referrals may or may not be appropriately made to surgical outpatients. Surgical outpatients may be overburdened with a variety of referrals, and unsurprisingly, surgeons that perform high volumes of laparoscopic cholecystectomies have longer wait times for review and subsequent surgery. (19) 
The detrimental effects of biliary colic affect patients, the healthcare network and society. Complications of gallstones, including pancreatitis, cholangitis and choledocolithiasis may be potentially life threatening (7). Recurrent episodes of acute biliary pain increase patient morbidity, and have associated social implications including loss of labour and income and their follow on effects. $(20,21)$

It is widely accepted that early laparoscopic surgery for acute cholecystitis is preferable to delayed surgery. The pathophysiological conditions often cited as barriers to surgery in acute cholecystitis, such as severe inflammatory changes, are less prevalent in cases of biliary colic and the risk of iatrogenic bile duct injury appears to be lower in biliary colic compared to cholecystitis (22). Recurrent episodes of acute biliary pain that occur whilst awaiting operative management may result in pericholecystic adhesions which may contribute to technical difficulties and surgical morbidity. Lessons can also be learnt by comparing the outcomes of early laparoscopic cholecystectomy for acute cholecystitis with delayed surgery. Meta-analyses of trials comparing early vs. delayed cholecystectomy show no significant differences in rate of conversion to an open procedure, (19.7 vs $22.1 \%)$ or rate of bile duct injury $(0.4$ vs $0.9 \%) .(23,24)$

In this study, 391 of the 584 patients proceeded to cholecystectomy. There were no instances of operative bile duct injury. There were three cases of post-operative bile leak, all of which were Strasberg 'Type A' leaks. (25) The three post-operative leaks were recognised in the initial postoperative inpatient period, one occurring in Group A (before policy implementation) and two in Group B. The three patients were managed with ERCP and trans-ampullary stent placement, each patient went on to have elective ERCP at 6-8 weeks post operatively, confirming resolution of the 
leak and allowing for stent removal. None of these patients suffered from long term biliary complications from the procedure. A single patient from Group B did, however, require radiologically-guided percutaneous drainage of a 'biloma' in the initial post-operative period and subsequently developed a pulmonary embolus that necessitated long term anticoagulation. The three patients who suffered from bile leaks underwent surgery on their index presentations with biliary colic.

A 2008 review of patients with complicated gallstone disease encompassing gallstone pancreatitis, symptomatic CBD stones, acute cholecystitis or acute biliary pain, indicated that $57 \%$ of the cohort experienced warning attacks of biliary colic. (7) In the same study, of the 53 patients with biliary pancreatitis, $10(19 \%)$ developed necrosis requiring extended hospital stay with a median of 40 days. This reflects the potentially serious complications of untreated symptomatic biliary disease.

In addition to the impact on patients, representations to the ED increases the burden on hospital resources and healthcare costs. A study of unplanned readmissions for biliary complications whilst on a waiting list for laparoscopic cholecystectomy estimated the overall cost to be approximately AU\$6129 (excluding ED costs and investigations), compared with AU\$3725 for elective admissions. (26) A review of 84 patients over a 12 -month period from a single centre in the UK identified savings of $£_{6} 695,918$ through implementation of early cholecystectomy. (27) Data from the USA shows that patients presenting to ED with acute biliary pain and then discharged on a pathway for elective cholecystectomy have a $20 \%$ chance of representing within 30 days. What is also not captured is the rate of presentations to general practitioners with biliary type pain and the time and resources lost to the community by these visits. (28) 
It must be acknowledged that not all patients are suitable for early laparoscopic surgery. Patient factors may necessitate the postponement of surgery, such age, medical comorbidities and the presence of anticoagulation. In this study we were unable to verify patient attitudes in determining discharge from the ED either due to social commitments or with the aim of seeking specialist care on their own.

The availability or lack thereof, of diagnostic imaging in the ED will impact on the speed of diagnosis and will also be a factor in delayed treatment. While in a tertiary setting, ultrasonography may be freely available in the ED, regional and district hospitals may not have such access. Patients presenting with acute biliary pain may be given a provisional diagnosis and planned for outpatient imaging and surgical outpatient follow up.

One of the main barriers to offering patients optimal care is the availability of acute resources to admit patients and undertake emergency surgery. Increasingly, Acute Surgical Units (ASU) have been developed acknowledging the need for services to provide timely surgery and the reallocation of resources in order to do so. Although the structure, implementation and strategy of the various ASUs may vary considerably, common features are the availability of admission beds, operating theatre access and staff. In our hospital four surgical units share on call duties but all cholecystectomies are undertaken by two specific units. While there is no ASU structure, two emergency theatres are staffed to function throughout daylight hours to provide emergency surgery and one at night. The presence of post fellowship sub-specialty trainees and the availability of day time emergency theatre access allows the majority of the emergency work to be undertaken within 48 hours without recourse to after-hours operating, displacement of elective cases or the need for an acute surgical unit 
structure. The follow-on effect of this mobilisation of resources is a reduction in length of stay, which is a core component in reducing costs of emergent surgery. (29)

This study has shown that a policy of admission to hospital for a first presentation of acute biliary colic is feasible and carries benefits for both patients and health services. Yet, despite the implementation of the new policy nearly $40 \%$ of patients were not admitted for various reasons. The third cohort in our study exposed an erosion in the implementation of the policy over time, leading to the number of patients undergoing surgery on their index presentation to decline. A number of factors such as unavailability of beds in the hospital or patients electing to be operated on in the private sector may have contributed to this. This study, however, was not designed to explore those in detail. Despite less stringent implementation, there was still a low representation rate compared to before the policy was introduced, potentially suggesting better patient selection for surgery on first presentation. Given the high likelihood of recurrent symptoms and representations those patients who are not admitted on their first presentation should undergo prompt follow up, investigation and surgery preferably within 30 days. Our study further demonstrates the importance of periodic review and evaluation of policies to maintain any clinical gains over time.

\section{References}

1. Glambek IK, G. Arnesjo, B. Soreide, O. Prevalence of gallstones in a Norwegian population. Scandinavian Journal of Gastroenterology. 1987; 22: 1089-94.

2. Muhrbeck OA, Ahlberg J. Prevalence of gallstone disease in a Swedish population. Scandinavian Journal of Gastroenterology. 1995; 30: 1125-8.

3. Jorgensen T. Prevalence of gallstones in a Danish population. American Journal Epidemiology. 1987; 126: 912-21.

4. Berger MvdVJ, Lijmer JG, de Kort H, Prins A. Abdominal symptoms: do they predict gallstones? A systematic review. Scandinavian Journal of Gastroenterology 2000; 35(1): 70-6. 
5. Shabanzadeh DM, Sørensen LT, Jørgensen T. A Prediction Rule for Risk Stratification of Incidentally Discovered Gallstones: Results from a Large Cohort Study. Gastroenterology 2016; 150(1): 156-167

6. Attili ADS, A. Capri, R. Repice, A. Maselli, S. The natural history of gallstones: The GREPCO experience. Hepatology. 1995; 21(3): 656-60.

7. Besselink M, Venneman N, Go P, Broeders I, Siersema P, Gooszen H, et al. Is Complicated Gallstone Disease Preceded by Biliary Colic? Journal of Gastrointestinal Surgery. 2009; 13(2): 312-7. 8. Halldestam IE, EL. Kullman, E. Borch, K. . Development of symptoms and complications in individuals with asymptomatic gallstones. British Journal of Surgery. 2004; 91(6): 734-8.

9. McSherry CF, H. Calhoun, WF. The natural history of gallstone disease in symptomatic and asymptomatic patients. Annals of Surgery. 1984; 202: 59-63.

10. Thistle JL CP, Lachin JM. The natural history of cholelithiasis: the National Cooperative Gallstone Study. Annals of Internal Medicine. 1984; 101: 171-5.

11. Gurusamy KS, K. Fusai, G. Davidson, BR. Early versus delayed laparoscopic cholecystectomy for biliary colic. Cochrane Database of Systematic Reviews. 2008; 4.

12. Cheruvu CV E-BI. Consequences of prolonged wait before gallbladder surgery. Annnals of the Royal College of Surgeons of England. 2002; 84(1): 20-2.

13. Mcafee DA HD, Bouliotos G, Breckingham IJ, Whnes DK, Lobo DN. Prospective randomized trial using cost-utility analysis of early versus delayed laparoscopic cholecystectomy for acute gallbladder disease. British Journal of Surgery. 2009; 96: 1031.

14. Salman BY, O. Irkörücü, O. Akyürek, N. Tezcaner, T. Dogan, I. Erdem, O. Tatlicioglu, E. Urgent Laparoscopic Cholecystectomy Is the Best Management for Biliary Colic. Digestive Surgery. 2005; 22(1-2).

15. Epari KP, Mukhtar AS, Fletcher DR, Samarasam I, Semmens JB. The outcome of patients on the cholecystectomy waiting list in Western Australia 1999-2005. ANZ Journal of Surgery. 2010; 80(10): 703-9.

16. Rutledge D, Jones D, Rege R. Consequences of delay in surgical treatment of biliary disease. The American Journal of Surgery. 2000; 180(6):466-9.

17. Guirguis LT, Taylor E. The complications of cholelithiasis caused by state authorisation delays. Surg Endosc. 1995; 9: 974-6.

18. Williams T DFAD, Kimbrough T, Riall T. Hospital Readmission After Emergency Room Visit for Cholelithiasis. Journal of Surgical Research. 2015; 197: 318.

19. Lau R VB, Porter G. Factors influencing waiting times for elective laparoscopic cholecystectomy. Canadian Journal of Sugery. 2007; 50(1): 34.

20. Kennedy CG, F. Brown, C. Taylor, E. . The impact of state approval requirements on elective cholecystectomy patients. Americal Surgery. 1995; 61:865-7.

21. Oudhoff JP, Timmermans DRM, Knol DL, Bijnen AB, Van der Wal G. Waiting for Elective Surgery: Effect on Physical Problems and Postoperative Recovery. ANZ Journal of Surgery. 2007; 77(10): 892-8.

22. Tornqvist B WA, Zheng Z, Ye W, Nilsson M. Severity of Acute Cholecystitis and Risk of Iatrogenic Bile Duct Injury During Cholecystectomy, a Population Based Case Control Study. World Journal of Surgery. 2016; 40(5): 1060.

23. Cao A EG, Cox M. Early Cholecystectomy Is Superior to Delayed Cholecystectomy for Acute Cholecystitis: a Meta-Analysis. Journal of Gastrointestinal Surgery. 2015; 19: 848. 
24. Verna S AP, Bali R, Sing R, Talwar N. Early versus delayed Laparoscopic Cholecystectomy for Acute Cholecystitis: a prospective randomised trial. Minimally Invasive Surgery. 2013; 2013.

25. Strasberg SM, Hertl M, Soper NJ. An analysis of the problem of biliary injury during laparoscopic cholecystectomy. J Am Coll Surg. 1995; 180:101-125.

26. Lawrentschuk N, Hewitt PM, Pritchard MG. Elective Laparoscopic Cholecystectomy:

Implications of Prolonged Waiting Times for Surgery. ANZ Journal of Surgery. 2003; 73(11): 890-3.

27. Seager A HT, Dennison A, Garcea G. Economic Implicatins of Providing Emergency

Cholecystectomy for All Patients with Billiary Pathology: A Retrospective Analysis. Surg Laparosco Endosc Percutan Tech. 2015; 21.

28.Bingener J TK, McConico A, Hess E, Habermann E. Sucess of Elective Cholecystectomy Treatment Plans after Emergency Department Visit. Journal of Surgical Research. 2015; 193:95. 29.Schwartz D SA, Zogg C, Nicholas L, Velopulos C, Efron D, Schneider E, Haider A. Operative delay to laparoscopic cholecystectomy: Racking up the cost of health care. Journal Trauma Acute Care Surgery. 2015; 18:1616.

\section{List of Supporting Information}

Table S1 - Types of first representation, $\mathrm{n}$ (\% of those who represented).

Table S2 - Representation rates whilst waiting for elective cholecystectomy. 


\section{University Library}

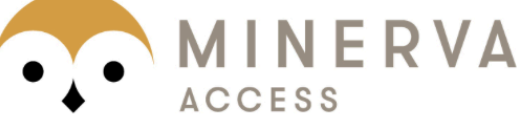

A gateway to Melbourne's research publications

Minerva Access is the Institutional Repository of The University of Melbourne

Author/s:

Cox, DRA;Fong, J;Liew, CH;Goh, SK;Yeoh, M;Fink, MA;Jones, RM;Mukkadayil, J;Nikfarjam, M;Perini, MV;Rumler, G;Starkey, G;Christophi, C;Muralidharan, V

Title:

Emergency presentations of acute biliary pain: changing patterns of management in a tertiary institute

Date:

2018-12-01

Citation:

Cox, D. R. A., Fong, J., Liew, C. H., Goh, S. K., Yeoh, M., Fink, M. A., Jones, R. M., Mukkadayil, J., Nikfarjam, M., Perini, M. V., Rumler, G., Starkey, G., Christophi, C. \& Muralidharan, V. (2018). Emergency presentations of acute biliary pain: changing patterns of management in a tertiary institute. ANZ JOURNAL OF SURGERY, 88 (12), pp.1337-1342. https://doi.org/10.1111/ans.14898.

Persistent Link:

http://hdl.handle.net/11343/284756 